BULLETIN Bulletin hispanique

HISPANIQUE Université Michel de Montaigne Bordeaux

114-2 | 2012

Varia

\title{
El adversario del profeta
}

Estrategias discursivas de conversión de los judíos y reforma de costumbres en un sermón de Vicente Ferrer

Carolina M. Losada

\section{(2) OpenEdition}

1 Journals

Édition électronique

URL : https://journals.openedition.org/bulletinhispanique/2194

DOI : 10.4000/bulletinhispanique.2194

ISSN : 1775-3821

Éditeur

Presses universitaires de Bordeaux

Édition imprimée

Date de publication : 31 décembre 2012

Pagination : 823-838

ISBN : 978-2-86781-855-4

ISSN : 0007-4640

Référence électronique

Carolina M. Losada, «El adversario del profeta », Bulletin hispanique [En ligne], 114-2 | 2012, mis en

ligne le 05 janvier 2016, consulté le 01 août 2022. URL : http://journals.openedition.org/

bulletinhispanique/2194; DOI : https://doi.org/10.4000/bulletinhispanique.2194 


\title{
El adversario del profeta: Estrategias discursivas de conversión de los judíos y reforma de costumbres en un sermón de Vicente Ferrer ${ }^{1}$
}

\author{
Carolina M. Losada \\ CONICET - UBA
}

Le cas du sermon XI de la campagne castillane de Vincent Ferrer permet de mettre en évidence les stratégies du prédicateur pour élaborer un ethos de prophète dont la fonction est liée à l'objectif essentiel de réforme des mours, en se servant d'une manière hautement originale des procédés rhétoriques à sa disposition.

Mots-clés: réforme des mœurs, prédication, Castille, prophétie, anti-Judaïsme médiéval.

El caso del sermón onceno de la campaña castellana de Vicente Ferrer permite dilucidar las estrategias con que el predicador construia un ethos de profeta cuya función se enlaza con el propósito mayor de alcanzar la reforma de costumbres, apelando a los recursos retóricos disponibles de un modo altamente original.

Palabras claves: reforma de costumbres, predicación, profecía, antijudaismo medieval, Castilla.

The case of the eleventh sermon in Vincent Ferrer's Castillan campain, allows us to draw into light the preacher's strategies in order to elaborate a prophet's ethos. Its function will be linked with the essential objective of reformation of manners, using, in a highly original way, the rhetorical processes at his disposal.

Keywords: reform of manners, prophecy, predication, Medieval Anti-judaism, Castille.

1. Este trabajo forma parte de la investigación «Vicente Ferrer y el fenómeno de la predicación popular en el Occidente Europeo: Cultura vernácula, reforma de costumbres e intolerancia religiosa en el otońo de la Edad Media.» que estoy llevando a cabo en el marco del Doctorado en Filosofía y Letras de la Universidad de Buenos Aires (Argentina) desde el año 2008, con una beca doctoral otorgada por el Consejo Nacional de Investigaciones Científicas y Técnicas (CONICET). Agradezco enormemente la atenta lectura y comentarios que de este artículo hicieron Guillermo Mehaudy, Constanza Cavallero y Santiago Peńa. 


\section{INTRODUCCIÓN}

La sociedad medieval fue una sociedad primordialmente oral. El mundo de lo escrito escapaba a la inmensa mayoría de la población y los sermones y el chisme acaparaban los roles de comunicadores sociales. Es por eso mismo que la palabra dicha y oída se convierte en una de las fuentes históricas significativas con las que contamos para ingresar al mundo cultural medieval ${ }^{2}$.

El caso de la campaña castellana de Vicente Ferrer (Valencia 1350- Vannes 1419) es uno más de una miríada de discursos en cuyo contenido y forma podemos comenzar a hallar las estrategias profundas con que se emprende la conversión de los judíos y la reforma de costumbres. A través de las herramientas proporcionadas por la lingüística-más específicamente del Análisis del Discursointentaré profundizar sobre los modos en que el predicador valenciano construía durante la campańa castellana de 1411-1412 a un adversario y a su propio ethos. Emprenderé aquí el estudio de un sermón en particular, el onceavo de la colección de la Real Academia Española de sermones de la campaña castellana del predicador valenciano durante 1411-1412, titulado en la colección como «Sermón onceno»". Los sermones predicados en Castilla por el maestre Vicente -cuya fama lo convirtió en el más célebre predicador de su época- resumen los objetivos generales de la predicación del futuro Santo; Ferrer buscaba la reforma de costumbres de los cristianos, la conversión masiva de los judíos y lo hacía a través de la amenaza escatológica. El sentido ${ }^{4}$ de este sermón y su contexto histórico lo hacen extremadamente relevante, por varias razones: fue predicado luego de la promulgación de las leyes de Ayllón, el aparato legal más restrictivo antijudío de su época y en comparación con otras fuentes que contienen el mismo sermón -los mismos sermones eran predicados en distintos lugares-, contiene referencias, alocuciones y argumentos para y contra los judíos.

El sermón plantea abiertamente la necesidad de conversión de los judíos a través de una explícita estrategia que consiste en la amenaza y la persuasión. Para ello Ferrer pone en juego alusiones al poder político y al fin del mundo (amenazas de castigo terrenal y ultraterrenal) y aserciones sobre la salvación

2. El valor inherente de la palabra dicha en el mundo medieval ha sido citado y analizado ampliamente, para una introducción historiogáfica sobre el concepto de 'comunicación' en los estudios históricos medievales véase Marco Mostert, 'New Approaches to Medieval Communication', New Approaches to medieval communication, Turnhout, Utrecht Studies in Medieval Literacy 1, 1999, pp. 16-37; también el análisis clásico de Walter Ong en, Orality and Literacy, London, Methuen \& Co. Ltd, 1982.

3. La colección de sermones de la RAE fue recopilada y transcripta por Pedro Cátedra García, (ed. y transc.), Sermón, sociedad y literatura en la Edad Media, Madrid, Junta de Castilla y León, 1994.

4. Por sentido del discurso entiendo un conjunto de indicaciones que se refieren a su enunciación, siendo ésta el nivel en el que se construyen en el discurso, la imagen de aquel que habla, de aquel a quien habla y las relaciones complejas entre esas entidades, a diferencia de la significación que está relacionada con las características semánticas del enunciado. O. Ducrot, Le dire et le dit. Paris, Minuit, 1984 (cito por edición en castellano, El decir y lo dicho, Buenos Aires, Paidós, p. 184). 
futura y la no contradicción entre las creencias básicas del judaísmo y el cristianismo.

La comunidad judía, a diferencia de las construcciones de estereotipos míticos -rasgo característico de la temprana modernidad-, tiene una presencia concreta y visible en el seno de la cristiandad'5 . El lugar del judío en una sociedad cristiana pretendidamente universal ${ }^{6}$ había sido resuelta por Agustín de Hipona, quien les había asignado un lugar en la economía de salvación de las almas. En el argumento agustino los judíos no merecían vivir en la sociedad cristiana por sus propios méritos, pues fallaron al no reconocer en Cristo al Mesías y además cometieron el más terrible de los delitos: el deicidio. A pesar de esto, arguye Agustín, Dios los preservó para el bien de la Iglesia con el objetivo de que los judíos, seguidores del Antiguo Testamento, atestiguaran la verdad de la base histórica para la profecía cristológica y, en última instancia, aceptaran las implicancias de esta profecía convirtiéndose al cristianismo al final de los días. La dispersión y degradación de los judíos asegurada por la Iglesia-afirma Agustín - aliviaría el problema potencial de una invasión judía a la cristiandad y enfatizaría el valor moralizante de su supervivencia, al remarcar la deplorable desgracia que les había traído el error de no reconocer al verdadero Mesías 7 .

El pensamiento agustino determinaba el rol específico de los judíos en una sociedad en la que la religión detentaba un discurso universal legitimador de las relaciones de poder. Al mismo tiempo aseguraba que no fueran eliminados de la cristiandad, e imponía una serie de límites para la interrelación social entre el grupo dominante y el dominado ${ }^{8}$. La teoría resolvía la ambigüedad de la presencia judía concibiendo a este pueblo como «un vestigio» $(\text { remnant })^{9}$, que además incluía una perspectiva escatológica en la que se insertaba la conversión masiva de los judíos como signo del fin del mundo. A partir de estas premisas se definirá un modelo de discriminación ideológica y práctica cuya evolución, en el caso de los reinos hispánicos, ni siquiera acabará con la expulsión, dada su proyección en el problema converso. Ahora bien, es claro que las premisas agustinas serán interpretadas por los actores sociales a la luz de su propio contexto histórico.

Los discursos antijudíos medievales responden a ciertos constreñimientos «teóricos» a partir de lo establecido por la Iglesia, pero todo discurso implica unas dinámicas interna y externa que han de ser abordadas para comprender

5. Sobre esta cuestión en la España moderna véase Fabián Campagne, Strix Hispánica, Demonología cristiana y cultura folklórica en la España moderna, Buenos Aires, Prometeo, 2009.

6. Brett E. Whalen, Dominion of god. Christendom and Apocalypse in the Middle Ages, Cambridge, Harvard University Press, 2009.

7. Agustín de Hipona, De civitate dei, 18.46. Traducción castellana de Miguel Fuentes Lanero, Obras Completas de San Agustín, Tomos XVI y XVII, Madrid, Biblioteca de Autores Cristianos, 2004, pp. 515-517. Véase también Idem, 20.29, pp. 736-738. Así como Tractatus adversus Judeos, PL 42,VI.7, VII.9, IX.12, traducción castellana Teodoro, Obras Completas de San Agustín, Tomo XXXVIII, Madrid, Biblioteca de Autores Cristianos, 2004, pp. 858-879.

8. Jeremy Cohen, The friars and The Jews, The evolution of medieval antijudaism, London, Cornell University Press, 1982, p. 21.

9. Ibidem. p. 178. 
la complejidad del problema del antijudaísmo. Las perspectivas sobre la propagación de los discursos y prácticas antijudías en el medioevo tienden a asumir una unicidad de las lecturas y los discursos perpetuando el mito de un antijudaísmo homogéneo, de carácter ideológico y estático. La historización del antijudaísmo debe abordar la interpretación de sus discursos, en tanto la otredad es siempre un tema de poder antes que de esencias ontológicas. En definitiva, los discursos que construyen al otro como sujeto son representaciones interesadas en la capacidad de acción sobre lo diferente ${ }^{10}$. Aquí intentaré dar cuenta de la significación del sermón como discurso político, de las estrategias discursivas puestas en juego y de la construcción del ethos del locutor con el objetivo de ahondar en la comprensión de la palabra dicha y oída como herramienta esencial de la comunicación social medieval, punta de lanza del control social y de la conexión entre los espacios (obliterados muchas veces por la historia) entre religión, política, poder y sociedad.

El objetivo de este trabajo es comprender la, valga la redundancia, doble duplicidad en el discurso antijudío vicentino. Al visualizar uno entre una gran variedad de discursos antijudíos podremos comenzar a raspar la superficie de la idea de estereotipo como algo homogéneo y ahistórico y comprender el sermón medieval como un ente complejo y dinámico que excede el objetivo transparente propuesto por el propio locutor. Por un lado veremos el funcionamiento de la compleja destinación de un discurso tradicionalmente leído como puramente antijudío. Así, al ocuparnos del rol del judío en el discurso desde una perspectiva constructiva y no reduccionista, nos acercaremos a una idea más cabal del lugar simbólico que este ocupa en la economía de salvación cristiana proyectada desde el púlpito y no desde la literatura. Por otro lado veremos los modos en que la polifonía sostiene la construcción de un ethos de profeta y cómo esta visión proyectada de sí que propone Ferrer abona la pretensión básica del predicador de reforma moral y de costumbres ${ }^{11}$.

10. Fabián Campagne, «El otro-entre-nosotros, funcionalidad de la noción de superstitio en el modelo hegemónico cristiano (España, siglos XVI-XVII)» Bulletin Hispanique, T. 102, 2000, p. $40-41$.

11. Se ha asumido tradicionalmente, gracias a la popularidad de Ferrer como santo y a las hagiografías preparadas luego de su canonización, el gran peso que tuvo San Vicente en el proceso de conversión de miles de judíos durante su labor homilética a través de Europa occidental. Entre los trabajos más recientes que citan o remiten al peso de San Vicente Ferrer en el antijudaísmo medieval están: Amran Rica, Judios y Conversos en el reino de Castilla, Madrid, Junta de Castilla y León, 2009; Yitzhak Baer, History of the Jews in Christian Spain, Tomo I-II, Skokie- Illinois, Varda Books, 2001 (1945); Julio Valdeón Baruque, El Chivo Expiatorio, Judios, revueltas y vida cotidiana en la Edad Media, Valladolid, Ámbito, 2000; Jeremy Cohen, op.cit; José María Monsalvo Antón, Teoría y Evolución de un conflicto Social, El antisemitismo en la baja Edad Media, Madrid, Siglo XXI,1985; Miri Rubin, Gentile Tales, The Narrative Assault on Late Medieval Jews, Philadelphia, University of Pennsylvania Press, 1999; Joan Young Gregg, Devils Women and Jews, Reflections of the other in Medieval Sermon, New York, SUNY, 1997, entre otros. 


\section{NuEVOS ACERCAMIENTOS AL SERMÓN COMO DISCURSO}

El discurso homilético es, entonces, una vital pieza del análisis de la cultura medieval, pues pone en escena un acto de habla cuyas implicancias culturales abarcan la comunicación de aspectos religiosos, políticos y sociales desde la palabra de un locutor ${ }^{12}$. El discurso del predicador popular, eminentemente pedagógico y prescriptivo, se manifiesta en un tiempo crónico. Este hecho nos insta a abandonar el paradigma que pretendía pensar los diversos emergentes de la vida humana como espacios estancos y abordar el objeto desde una lectura problematizadora ${ }^{13}$. El sermón, entonces, es un acto de habla (lo cual implica tomar en cuenta al locutor y al alocutario ${ }^{14}$ ) que ocurre en un tiempo crónico (histórico) significativo y que carga con ciertos - no pocos- contenidos culturales.

La predicación es un medio de comunicación, entonces, dicho y oído, una interacción entre predicadores y sus audiencias ${ }^{15}$. El problema ha sido siempre capturar la oralidad de la palabra y con ella la temporalidad de los sermones. Éstos aparecen primordialmente en sermonarios -ediciones formales de recopilaciones de sermones, cuyo uso es educativo para el clero en formación-, sin embargo, hace pocas décadas se ha comenzado a prestar atención al sermón producido por reportators, sermones estenográficos transcriptos en el momento de su enunciación ${ }^{16}$. Las palabras de estos escritos son lo más cercano que encontramos a una transcripción de la verdadera oralidad del acto de predicación, reconociendo sus naturales limitaciones en el hecho de que muchos reportators traducían simultáneamente. Este sermón aparece entonces inserto en una temporalidad (yo-aquí-ahora) y no queda perdido en un ideal abstracto. La intersubjetividad brota de estas recopilaciones permitiendo un análisis de un rasgo esencial del objeto-discurso ${ }^{17}$. La reposición del contexto

12. Dominique Maingueneau, «Ethos, scénographie, incorporation», en Amossy, R. (dir.) Images de soi dans le discours, Lausanne, Delachaux et Niestlé, 1999, pp. 75-100

13. Me propongo aquí utilizar el concepto de problematización de Michel Foucault, quien desarrolla esta idea a partir de la necesidad del cientista social -en este caso, él mismo- de plantear preguntas (posing a problem) considerando al mismo tiempo una lectura de la organización de representaciones y un trabajo individual de pensamiento. Así el concepto de problematización habilita a una lectura del dominio de la acción, del comportamiento que asume que la acción está atravesada por la estructura social, política, económica y cultural de los actores y que ese entorno habilita un repertorio de actos que deben ser tenidos en cuenta. Michel Foucault, «Polemics, politics and problematization: an interview with Michel Foucault», en Paul Rabinow (ed.), Essential works of Michel Foucault, Vol 1: Ethics, Subjetivity and Truth, London, Allen Lane, 2000.

14. Usaré, en este texto, los términos alocutario y destinatario de modo intercambiable siendo consciente de que en sus diferencias existe un debate lingüístico. Sin embargo, a los fines de este trabajo las diferencias entre ambos es relativa.

15. Thompson, A. O.P, «From texts to preaching: retrieving medieval sermón as an event», Muessig, C. (ed.), Preacher, Sermon an audience in the Middle Ages, Leiden- Boston- Köln, Brill, 2002, p. 15.

16. Ibid, p. 17.

17. María Marta García Negroni y María Tordesillas Colado, La enunciación en la lengua, de 
histórico es necesaria, en tanto es posible y habilita una ampliación del estudio del discurso en su contenido y forma como emergente social de un tiempo determinado y de un locutor y un alocutario determinados.

El tiempo de la enunciación, como ya lo establecía Benveniste, está marcado por variables objetivas y subjetivas que determinan el teatro, la escena de la misma ${ }^{18}$. Siguiendo el concepto de Ducrot, la realización del enunciado es un acontecimiento histórico: existe como algo nuevo aún cuando su estructura semántica haya existido en otros discursos ${ }^{19}$. De esta manera, al ser observado desde la concepción de Ducrot sobre la diferenciación entre significación y sentido, el sermón onceno de la campaña castellana tiene una significación ${ }^{20}$ histórica específica y especial en relación a la cuestión del antijudaísmo en Vicente Ferrer y a las estrategias de persuasión para la conversión de los judíos y para la reforma de costumbres de los cristianos por el otro $^{21}$. Dicho contexto debe ser tenido en cuenta ya sea cuando pensemos en el ethos pre discursivo ${ }^{22}$ como cuando analicemos la escena enunciativa ${ }^{23}$. Enunciado en agosto de 1411, el Sermón onceno de la campaña castellana se enmarca no sólo en la campaña de predicación del santo sino además en los meses previos a la promulgación de las violentas leyes antijudías de enero de 1412. Las leyes de Ayllón o Pragmática de Catalina de Lancaster fueron una síntesis clara del pensamiento de San Vicente y son mostración de su influencia en los poderes seculares de la región ${ }^{24}$. La pragmática de Catalina de Lancaster ha sido señalada como la legislación más dura contra los judíos nunca antes promulgada ${ }^{25}$. En el programa antijudío, que se proyecta desde la prédica de San Vicente hacia las leyes de Ayllón, subyace la idea de que la limitación efectiva de la participación de los judíos en las actividades económicas, políticas y sociales dentro de la comunidad cristiana, tendrá como consecuencia una masiva conversión voluntaria. El

la deixis a la polifonía, Madrid, Gredos, 2001, p. 75.

18. D. Maingueneau, op. cit., p. 82.

19. O. Ducrot, op. cit., p. 183.

20. Concebida esta como «un conjunto de instrucciones dadas a las personas que tienen que interpretar los enunciados de la frase, instrucciones que establecen las maniobras que se van a realizar para asociar un sentido a estos enunciados». Conocer la significación del enunciado incluye el momento y el lugar de su enunciación. Ibid, p. 185.

21. Ibid, p. 184

22. D. Maingueneau, op. cit., p. 86.

23. M. M García Negroni y M. Tordesillas Colado, op. cit., p. 75.

24. Ricardo Muñoz Solla ha detectado ya las estrategias de persuasión en los sermones 7 y 11 de la campańa castellana, poniendo el énfasis en los mecanismos para-lingüísticos como estrategia de persuasión. Sin embargo deja de lado el funcionamiento completo del discurso en una situación más amplia y la existencia de una audiencia compleja y superpuesta que abordo en este trabajo. "Estrategias de persuasión y oyentes judíos en dos sermones de san Vicente Ferrer», El Olivo XXIII, n 49, 1999, pp. 25-43.

25. Benzion Netanyahu, The Origins of the Inquisition in Fifteenth-Century Spain, New York, Random House, 1995 (cito por la edición castellana, Los orígenes de la Inquisición en la España del siglo XV, traducida por Ángel Alcalá Galve y Ciriaco Morón Arroyo, Barcelona, Crítica, 2000, p. 171). 
hecho de que precisamente la Corona de Castilla, una de las monarquías que tradicionalmente más había protegido a las comunidades judías, promulgara las leyes antijudías más restrictivas del medioevo, expresa la trascendencia del predicador y la importancia de sus sermones tanto en el ámbito popular como en el de los círculos de poder político y religioso ${ }^{26}$.

\section{ESTRATEGIAS DISCURSIVAS DE CONSTRUCCIÓN DEL ADVERSARIO}

Siguiendo la idea de polifonía enunciativa de Ducrot, podemos intentar analizar el sermón como un encadenamiento de enunciados cuya contraparte, el alocutario, desaparece en el mutismo de los raporters y aparece solo bajo la luz de un análisis histórico ${ }^{27}$. El discurso homilético, para muchos autores, parecería ingresar en la categoría de discurso monológico, de autor. Su análisis consistiría en una interpretación de su objetivación individual como emisor único del enunciado. Sin embargo, para nuestro objetivo es más útil pensar el discurso como un diálogo, mucho más en tanto discurso público, popular y con tal contenido social y político. El discurso de Vicente Ferrer está cargado de polifonía -y no sólo como discurso referido-, se hallan enunciaciones en las que el locutor aborda contenidos culturales tales como el arquetipo del judío, el clero, el pueblo y la misma Iglesia, que no alcanzaremos a analizar aquí.

La estructura analítica que desarrolla E. Verón para comprender la destinación en el discurso político resulta útil como punto de partida para analizar el discurso onceno de la campaña castellana. Más allá de las advertencias del autor respecto de la necesidad de aplicar el modelo analítico sólo a los discursos políticos enunciados en la democracia republicana, el mismo modelo es pasible de ser aplicado en otros contextos de discursos sociales, en este caso, el religioso/político. La construcción del adversario -que para Verón implica una modelización abstracta que permite la construcción de una imagen dentro del discurso- en el discurso político implica una doble o triple destinación simultánea ${ }^{28}$. Ahora bien, descubrimos que en el discurso de Ferrer el modo de destinación es intercambiable dependiendo de la enunciación y que la construcción de un adversario es menos clara de lo que aparenta. Para ahondar en este aspecto usamos la idea de multidestinación desarrollada por

26. Por caso debemos resaltar que las leyes de Ayllón fueron inspiradas en una legislación murciana también expedida luego del paso del predicador y cuya aplicación férrea y respeto popular le ganó una represión del regente Fernando de Antequera, pues los judíos murcianos se quejaban con él de que no podían, siquiera, comprar alimentos para mantenerse. Veáse «Carta del infante don Fernando a la ciudad de Murcia». Valladolid, 29 de Abril de 1411, "Apéndice», Juan Torres Fontes, «Moros, judíos y conversos en la regencia de Don Fernando de Antequera», Cuadernos de Historia de España, XXXI-XXXII, 1960, pág. 97.

27. O. Ducrot, op. cit., p. 203.

28. E. Verón, «La palabra adversativa. Observaciones sobre la enunciación política» en Verón et. al., El discurso politico: lenguajes y acontecimientos. Buenos Aires, Hachette, 1987, p. 17. 
M. M. García Negroni, quien plantea que es posible detectar destinatarios encubiertos o indirectos a través de las instrucciones o indicaciones mismas del discurso ${ }^{29}$.

El sermón inicia de un modo programático:

Buena gent, çerca esta palabra propuesta yo entiendo predicar e declarar oy quáles e quántas maneras son por las quales el nuestro señor e Salvador Ihesú Christo saca a las personas que están en buena vida cómo las promueve a mejor e a acresçentamiento de méritos. (...) E avremos algunos secretos de la sancta Scriptura para alunbramiento de jodíos e moros.(...) quatro son los aguijones con los quales nuestro Señor Ihesú Christo punge e aguijona a las personas que sson en mala vida e en pecado por que vengan a buena vida; e si están en buena vida vaya adelante, mejorando $(\ldots)^{30}$.

Planteado el objetivo del discurso de un modo característico de las ars praedicandi el locutor objetiviza tres destinatarios: uno general, los cristianos, y dos particulares a quienes se refiere en tercera persona: judíos y moros -no volverá a referirse a este último-. El propósito del sermón es general. El metacolectivo singular es la humanidad, no un grupo religioso ${ }^{31}$. La definición de los destinatarios indecisos o adversarios es confusa, pues en otros fragmentos encontramos complejos ilocucionarios ${ }^{32}$ en los que la enunciación explícita de la amenaza de la ira divina contra el metacolectivo singular oculta una enunciación dirigida en particular a los judíos:

E si en este aguyjón [se refiere al temor del juicio final] para mientes la criatura de buena ventura es. Ca si está en malas obras e en mala vida, este aguyjón le fará tomar el camino de buena vida e buenas obras. (....) E por este aguyjón fue convertido Sant Paulo (...). Ca dize en el libro Actuum Apostolorum, IX ${ }^{\circ} . c^{\circ}$., que sant Paulo fue el mayor enemigo de christianos que en el mundo nunca fue. E era muy honrrado omne e él mismo se fazía acusador e verdugo por matar a los christianos.(...) E assi yendo, catad que súbitamente vino tanta claridat del çielo, así como rrayo, e dio en él e écholo en la tierra. E nuestro Señor Ihesú Chsristo se le demostró e dixo "Salve, Salve ¿̨por qué me persigues? (...) Yo soy Ihesus de Nazareth, el cual tu persigues, señor e juez universal de todas las criaturas". E con este aguyjón de temor judicial ovo atán grand temor que vino a ser christiano $(\ldots)^{33}$.

29. M. M. García Negroni, «La destinación en el discurso político: una categoría múltiple», Lenguaje en contexto $I(1 / 2)$, pp. 85-111.

30. Vicente Ferrer, 1411-1412, «Sermón onceno» en Pedro Cátedra García (ed. and transc.), op. cit., p. 384 .

31. El concepto de destinatario «metacolectivo singular» es interesante y sin embargo, ambiguo. Presenta la idea de una enunciación dirigida a un destinatario mucho más amplio que aquellos grupos definidos por Verón como posibles alocutarios del discurso político. Probablemente en un estudio como el presente, en el que el análisis no es de un discurso político sino de un discurso religioso en un momento en que la Iglesia Católica se pretende voz universal de la espiritualidad del mundo conocido el metacolectivo singular en el discurso de Vicente Ferrer debe ser seńalado como la «humanidad» toda, al menos a efectos del ideal que está planteando. Para una definición más certera del concepto veáse: E.Verón, op. cit. , p. 18.

32. El concepto de "complejo ilocucionario» en los términos en los que está usado en este trabajo es desarrollado por M. M. García Negroni, en «La destinación en el discurso político: una categoría múltiple», p. 88.

33. Vicente Ferrer, «Sermón onceno», p. 382. 
Así, en el «asesino de cristianos» (un judío) hallamos una doble imagen: el pecador y el anti-cristiano, que gana el paraíso a través de la conversión. Estratégicamente Ferrer se propone la conversión no sólo de los judíos sino también de los malos cristianos a quienes considera tan malos como a los gentiles. La misma estrategia se invierte en otros fragmentos en los que la enunciación parece dirigida al contradestinatario judío (un contradestinatario que tiene mucho de paradestinatario en este contexto) pero contiene una enunciación derivada para el prodestinatario:

Ascuchad respuesta. Dí, jodío, ¿̇la noche quien la fizo si non Dios? Pues si Dios la fizo, buena es e conplida, ca Dios no faze cosa menguada. ¿Pues por qué fizo después venir el día claro, ca Dios non se muda? Ca aquel mismo Dios que fizo la noche para dormir e para folgar e reposar, aquél mismo faze el día claro para trabajar e ganar la vida. Assí la ley de Moysés buena e santa es, e diola Dios para folgar en la casa deste mundo, porque non promete sinon cosas terrenales, comer e beber e rriquezas, e es oscura, ca, cuando Dios la dio a Moysés, nunca le pudo ver la cara, más nesçesario era que veniese el día claro, esto es Ihesú Christo, quia "ortus solt e justicie" Christus deus noster.

E ves aquí el día claro del sol de justiçia Christo Dios nuestro, el qual dio la ley nueva non para alcançar la gloria celestial de paraíso ${ }^{34}$.

El fragmento inicia luego de una polémica en la que Ferrer toma la voz de los rabinos presentando un «teatro» al organizar diálogos internos al discurso en el que reproduce la crítica tradicional de los intelectuales judíos a los cristianos: que el Antiguo Testamento es también palabra divina y fue dado a los judíos y debe ser respetado como tal. El uso de la estructura interrogativa para desvalorizar la posición de los rabinos implica una negación metalingüística ${ }^{35}$, y es posible identificarlo como el discurso anti-garante ${ }^{36}$. La descalificación es absoluta, más aún si tomamos en cuenta el discurso en su totalidad y señalamos que la función de esta enunciación es de persuasión.

Además de pretender simplificar dos siglos de polémicas contra los rabinos de un modo comprensible para el vulgo y de reducir la polémica a una dinámica natural, Ferrer enuncia una aserción vital para sus propósitos generales: el cristianismo es espiritual, no desea cosas terrenales. En un mismo enunciado Ferrer cumple un doble objetivo: la exhortación a la conversión (a través de la de invalidación de los principios judíos) y a la reforma de costumbres (a través de una oposición, terreno-divino, de la ley de Dios y de la identificación del «buen cristiano» con aquél que busca la satisfacción espiritual). En ese sentido los tres grupos podrían ser considerados un único alocutario.

Es posible preguntarse, entonces, hasta qué punto el adversario construido en este sermón, que inicialmente parecería ser el judío, es en realidad el infiel, esto es no sólo a aquellos que no eran cristianos sino también a los cristianos que incumplían los preceptos básicos del cristianismo. Usualmente el debate

34. Ibid, p. 384.

35. M. M. García Negroni y M. Tordesillas Colado, op. cit., p. 75.

36. D. Maingueneau, op. cit., p. 84 
en torno a la figura de Ferrer tiende a concentrarse en el aspecto antijudío de estos discursos ${ }^{37}$, pero una mirada apenas más profunda a este, uno de los discursos más citados para probar el antisemitismo de Ferrer, parece indicarnos que la amenaza del castigo divino a los gentiles oculta una amenaza mucho más amplia. El discurso derivado, es cierto, tiene otro status enunciativo, pero la práctica de la polémica del discurso es una estrategia que apunta a la realización exitosa de las funciones persuasiva y de refuerzo de creencia ${ }^{38}$. Lo mostrado en este discurso a un nivel superficial es descalificación y amenaza para con los judíos y persuasión para con los cristianos. La argumentación, organizada para convencer a través de diversos niveles de intensidad de castigo, no está dirigida por turnos a los diversos alocutarios. Una amenaza paralela y similar está presente en la fuerza ilocucionaria oculta en los enunciados dirigidos al alocutario judío.

¿Qué decir entonces del judío como contradestinatario? En realidad, parece ser más un "destinatario dinámico», que es reprendido y amenazado pero incluido. Para comprender el lugar que ocupa como adversario construido en el discurso hay que remitirse al marco de la enunciación discursiva, pues resulta incomprensible desde el marco de un enunciado aislado ${ }^{39}$. Cuando se dirige a ellos lo hace de un modo polémico, pero también programático:

E por ende, jodíos, parat mientes en este joýzio e este temor vos fará venir a tornar al camino de la verdat e de la fe de Ihesu Christo ${ }^{40}$.

La amenaza es transparente y al mismo tiempo los incluye como parte del acto de habla. El locutor conmina a los judíos a la conversión. La contradestinación - directa en este caso- queda evidenciada y al mismo tiempo enriquecida por el uso de la segunda persona, pues el alocutario es reconocido como parte de la destinación directa y no sólo como metacolectivo singular al que es dirigido el encadenamiento de enunciados ${ }^{41}$. En tanto el judío es percibido como enemigo de la cristiandad, al mismo tiempo que está cautivo y sometido a múltiples presiones para formar parte del grupo de identificación, su lugar en la economía de salvación cristiana lo reconoce como «remnant» ${ }^{42}$. Sin embargo, no deja de ser identificado como un elemento subversivo. El adversario aparente no es el adversario real en este discurso. Una escena enunciativa fértil permite la construcción de un mecanismo de persuasión que combina la seducción de la vida eterna con la amenaza de la eternidad infernal:

37. Cf. Ricardo Múñoz Solla, op. cit.

38. M. M. García Negroni, «La destinación en el discurso político: una categoría múltiple», p. 89.

39. Ibid, p. 93

40. Vicente Ferrer, «Sermón onceno», p. 390.

41. En general, la marca léxica del adversario es la tercera persona (función polémica del discurso). En este caso, sin embargo, aquel alocutario que parece establecerse como contradestinatario recibe alocuciones en segunda persona. Veáse M. M. García Negroni, «La destinación en el discurso político: una categoría múltiple», p. 87.

42. Jeremy Cohen, op. cit., p. 178. 
E si en este aguyjón para mientes la criatura, de buena ventura es. Ca si está en malas obras e en mala vida, este aguyjón le fará tornar al camino de buena vida e de buenas obras; e si está en buena vida e en buenas obras fazerle ha continuar en ellas. E cata actoridat de David en psalmo Beati inmaculati (...) dize, 'Señor, puncha las mis carnes con el tu temor, ca grand miedo he de los tus joýzios ${ }^{3 / 3}$.

Volviendo a la estructura original del discurso, en la que la idea de los aguijones ahorma el argumento, este enunciado define el sentido del discurso de un modo simple. El locutor plantea tres posibles escenarios programáticos para los destinatarios (en este caso: buenos, malos potencialmente buenos, y malos) y define el futuro espiritual de cada uno de ellos. En el enunciado se detecta nuevamente una enunciación derivada: la mención de David como autoridad refiere claramente a los judíos y a la aceptación de esta dinámica de la relación humanidad-divinidad de parte de los patriarcas en la que el miedo es el correctivo preferido por Dios.

Aún más interesante resulta el siguiente fragmento:

Solamente este aguyjón de temor judicial devría abastar a convertir a los jodíos. Ca, jodíos, sabed que el verdadero rrey Mexías Ihesú Christo verná aýna a juzgar el mundo. E ya es venido una vez, ca mil e quatroçientos e doze años que es venido. Mas otra vez ha de venir a juzgar el mundo e estonçe cognosçerán los jodíos que Dios es omne $e^{44}$.

En una misma enunciación se refiere a los judíos en tercera persona, en segunda y luego en tercera nuevamente. Queda evidenciado aquí el complejo lugar de este destinatario en el sermón onceno. El cambio de persona confirma mi postura de que el alocutario no es fijo sino dinámico. La enunciación está dirigida a los cristianos y a los judíos y cada oración tiene su propia estructura verbal, pero no de sentido.

\section{LA PALABRA DEL PROFETA}

La transacción entre locutor (predicador) y alocutario (audiencias) resulta elusiva $^{45}$. Los sermones eran una forma ritualizada de comunicación cuya estructuración predeterminada reafirma el hecho de que el locutor, al decir de Bajtín, ha de acudir al arsenal de contenidos culturales cuya forma es dada por operaciones de ahormamiento estético ${ }^{46}$. Estas operaciones eran significativas en tanto detrás de ellas se encuentra una estrategia de parte del predicador: la conversión masiva de los judíos y la reforma de costumbres de los cristianos.

43. Vicente Ferrer, «Sermón onceno», p. 389.

44. Ibid., p. 389.

45. Respecto de esta interacción entre predicador y audiencia Rosa Vidal ha concluído que existió una amplia aceptación de las premisas del discurso de Ferrer durante la campaña castellana a partir de ciertos indicios históricos generada por la respuesta dramática que el el evento del sermón precipita. Rosa Vidal Doval, «Predicación y persuasión: Vicente Ferrer en Castilla, 14111412», Revista de poética medieval, 24, 2010, pp. 225-243.

46. Mikhail Bajín, Estética de la creación verbal, México, Siglo XXI, p. 258. 
La eficacia con que Ferrer logra convertir su propuesta en posible reside y se sostiene desde el ethos de un verdadero profeta. Esta figura religiosa, superior a la del santo, es común a las religiones del libro. El profeta es aquel que tiene o ha tenido una comunicación con la divinidad y cuya labor consiste en transmitir ese mensaje al mundo. Los profetas fueron las figuras principales que dieron forma a la/s religión/es para los judíos, católicos y musulmanes. Mahoma, Moisés, David, etc., son reconocidas figuras identificadas como profetas y es a este contenido cultural común al que Ferrer apela ${ }^{47}$.

¿Cómo logra Ferrer construir un ethos de profeta en un mundo religioso en el que las heterodoxias eran perseguidas? Construyendo múltiples legitimidades en espacios políticos diversos, como el Papado y las monarquías hispánicas. Prueba de la efectividad del discurso de Ferrer es que los íconos que lo_representaban rotulan al predicador "Ángel del Apocalipsis» y su canonización fue una de las más veloces de las realizadas en la época ${ }^{48}$. El ethos prediscursivo del predicador abarca no sólo una amplia fama social sino también una validación profética de las autoridades eclesiásticas. Llevaba el título de "Legatus a latere Christi» otorgado por el Papa, y con este se presentaba a las autoridades civiles para que autorizaran su predicación cuando no la habían solicitado ${ }^{49}$. Ferrer había tenido una revelación ${ }^{50}$ en 1389, en su lecho de enfermo, en la que Cristo le solicitaba que predicara antes del Fin del Mundo ${ }^{51}$. La visión iniciática de la vida evangelizadora de Ferrer se convierte en la punta de lanza de su discurso y su influencia como predicador. Él fue elegido por Cristo para anunciar el fin del mundo, por lo tanto su autoridad -según la carta papal que lleva consigo y que lo consigna como legado de Cristo- emana directamente del hijo de Dios.

El sermón onceno es uno de los muchos discursos en los que Ferrer construye su ethos de profeta. La situación de enunciación que hace el discurso onceno pertinente es creada por el mismo locutor, pues es él quien predica la llegada del fin del mundo y el consiguiente castigo divino:

E cata qué rrevelaçión tan maravillosa e tan excelente mostrava Dios a sant Paulo.

E después desto mostrávale las carçeles del infierno, e dezíale: -«Paulo, cata que en

47. Niels Christian Hvidt, Christian Prophecy, the post biblical tradition, New York, Oxford University Press, 2007, pp. 4-7.

48. José de Garganta O.P., Vicente Forcada, O.P. Biografía y escritos de San Vicente Ferrer, Madrid, La Editorial Católica, 1956, p. 80.

49. Joan Mira, San Vicente Ferrer, Vida y Leyenda de un predicador, Valencia, Bromera, 2005, p. 46 y José de Garganta O.P., Vicente Forcada, O.P. Ibid., p. 37.

50. "Revelations are inspired speech, a privileged discourse thats allows ordinary people to gain extraordinary authority when addressing the prelates and seculars rulers. But revelantions, with their mixture of autobiographical elements, political agendas and religiuos mandates, can also tell us much about medieval anxietis, hopes and expectations» Renate Blumenfeld Kosinski, Poets, Saints and Visionaries of the Great Schism 1378-1417, Pennsylvania, Pennsylvania University Press, 2006. p. 33

51. La cercanía del apocalipsis es uno de los aspectos básicos de la predicación de Ferrer. Carolina Losada, «San Vicente Ferrer y el Anticristo. Análisis de los sermones de la campaña castellana 1411-1412», Actas XI Jornadas Interescuelas / Departamento de Historia. San Miguel de Tucumán, 2007. 
aquellas cárçeles están los judíos e los moros; e en aquellas otras los malos christianos». E por estas tan maravillosas revelaciones que avía por ventura en el su coraçón alguna presunpçión de sobervia o de vanagloria, porque lo podiera todo perder ${ }^{52}$.

En la referencia a la revelación que Dios hizo a San Pablo (llamado «El profeta de los gentiles» por su incansable labor para convertir a los paganos) el mal cristiano recibe la misma amenaza de castigo que el infiel: todos son víctimas de la ira infernal. Ferrer se ubica como uno de los últimos profetas y así logra proyectarse como un estereotipo más amplio que el del predicador cristiano. La evocación de una serie de escenas validadas comunes a las religiones del libro lo separa de un ethos de predicador-para-los-cristianos y lo valida como predicador-para-el-mundo. Claramente el enunciador-como diría Maingueneau- legitima al enunciado ${ }^{53}$. Es la propia posibilidad del castigo la que permite a Ferrer construir su ethos de predicador y amenazar a todos sus destinatarios al tiempo que los conmina a convertirse.

E este dolor corporal fue siempre nesçesario a los judíos, que jamás nunca quisieron fazer cosa alguna de bien sinon con mal. E assí lo dyze la Sancta Scriptura Exodi XII․ $c^{\circ}$. Dize en este capítulo que quando los judíos avían de salyr del captiverio de Egipto, dize el testo que los egipçianos mismos los forçavan, diziendo que saliesen fuera del captiverio, ca non querían salir sinon perezosamente, en tanto que a empuxones los echavan fuera. E quando fueron fuera de Egipto, començaron a entrar por el desierto e llegaron a un paso muy angosto, que de la una parte estava una sierra montańa muy áspera e muy alta e de la otra parte estava la mar Bermeja. E los egipçianos venían en pos ellos armados para los fazer tomar o matarlos. E catad que se veýan en muy grant aprieto, ca nyn podían pasar la montańa que estava mucho alta nin la mar. Más nuestro Señor Dios dixo a Moysés: - "Moysés tañe con la virga el mar"-. E Moysés tanxó con la virga la mar e súbitamente la mar se partió e fizo doze carreras en seco. [...] Estonçe dixo a Rubén, que era el primogénito, que entrase primero. E non quixo, ca non osava entrar, que avía miedo que se tornaría la mar sobre él. E Moysés, desque esto vido, dixo a Simeón que entrase, e tampoco osó entrar. [...] E, finalmente, el primero que entró fue el tribu de Jafudá; e siguyeronlo luego los otros. [...]

Buena gent, catad que esta mar bermeja es el santo bautismo, ca la agua del baptismo es bermeja, por la pasión de nuestro Señor Ihesú Christo ${ }^{54}$.

El uso de la figura y las palabras Moisés -el gran profeta judío- para persuadir a los judíos de convertirse es altamente significativo en términos de estrategia discursiva. Hay una desvalorización de la exégesis veterotestamentaria hebrea opuesta a una relectura cristiana en las palabras del predicador. La escena de enunciación pretende un discurso directo en el que el locutor cita las palabras que Dios dirigió a Moisés. Dejando de lado las implicancias de la pretensión del locutor de conocer palabras de Dios que no se encuentran en el Antiguo Testamento, podemos observar cómo esta cita está dirigida a reformular un fragmento conocido por sus múltiples audiencias para convertirlo en una herramienta de conversión al tiempo que construye su ethos de profeta. Un

52. Vicente Ferrer, «Sermón onceno», p. 382.

53. D. Maingueneau, op. cit., p. 84

54. Vicente Ferrer, «Sermón onceno», pp. 383-384. 
profeta que no sólo pretende convencer a todos de la inminencia del fin del mundo sino que además tiene conocimiento de la verdadera historia de los judíos por versión divina.

E por esto, jodíos, esto es lo que avedes de fazer, que entredes en la mar Bermeja, que es el santo baptismo, que está abierto e tańido con la verga de la santa cruz e baptizadvos e seredes salvos, así e todos vuestros enemigos se afogarán. E los que se bautizaren primero o en medio o en çaga todos serán salvos. Mas, aunque todos sean salvos, así como pasaron la mar, mas aquél que entró primero, que fue el tribu de Jafudá, ganó corona rreal. Assí vosotros agora, los que primeros entrades en el baptismo ganaredes mayor corona, aunque todos vos salvedes. Ca la ordenación que el rey ha fecha que vengades a la predicación, por vuestra salvación es fecha, aunque venides por fuerça e con aguyjones e a mal de vuestro grado ${ }^{55}$.

La escena enunciativa es la convocatoria del rey a la predicación de Ferrer. Este pretende una adhesión progresiva de los alocutarios judíos a los que incluye como parte de su audiencia, no de sus adversarios - que he intentado probar en el apartado anterior- con el objetivo de convertir a todo aquel infiel -imagen potencialmente identificable con el metacolectivo singular, pues en términos de Ferrer todo pecador es pasible de castigo-. De cierta manera el garante de este discurso está asociado y validado por una superioridad del locutor, que ha sido otorgada por Dios con su revelación, por sobre todos los alocutarios. Así, la escena validad ${ }^{56}$ que usa el predicador es interior al discurso, intrínseca a los objetivos de Ferrer, y exterior a él, pues consiste en un discurso referido de los Testamentos.

Los modos de la construcción del anti-ethos en este discurso abonan la idea planteada más arriba, pues encarna a todo aquel que sea no-cristiano, infiel, y que no acepte la palabra de Dios del modo en que está siendo comunicada por Ferrer.

\section{CONCLUSIONES: Un ADVERSARIO PARA UN PROFETA}

En la sociedad medieval el sermón constituía una de las vías primordiales de comunicación cultural y fue el medio privilegiado para la reforma de costumbres en una sociedad en la que las estructuras efectivas de control políticoinstitucionales y religiosas eran, como mínimo, débiles. El predicador popular es, en este contexto, un personaje que cumple una serie de funciones, como comunicador social y como promotor de un ideal religioso de ser-cristiano. Es por eso que los sermones medievales se han convertido en una de las fuentes privilegiadas para el estudio de la cultura medieval. Ahora bien, la atención a

55. Ibid. p. 184.

56. El concepto de «escena validada» desarrollado por Maingueneau implica que el locutor aborda una serie de contenidos culturales que pueden ser fácilmente legibles por los destinatarios (o co-enunciadores) y comprensibles del modo en que el locutor lo desea. D. Maingueneau, op. cit., p. 86. 
los sermones tiende a orientarse hacia ideas preconcebidas del pensamiento y comportamiento histórico, y muchas veces acaba limitando al historiador a lecturas heredadas ${ }^{57}$.

He intentado en este trabajo abordar nuevas posibles lecturas del problema de la alocución a los judíos y el rol que estos ocupaban en la economía de salvación cristiana tal como fue planteada por uno de los más reconocidos predicadores populares de la Baja Edad Media. La empresa de repensar al sermón como un espacio dialógico, en el que los contenidos culturales previos toman una nueva forma estética y cuyo sentido debe comprenderse no sólo a través de la palabra sino también del modo, está necesariamente acompañado de una serie de herramientas metodológicas que no suelen usarse en el campo de la historia medieval y moderna.

La persuasión se explicita en este sermón como función del discurso de un modo singular. Comprende múltiples enunciaciones que, aparentemente, tienen objetivos diversos. Debe considerarse que el contexto en el que este discurso fue enunciado presentaba una alta fertilidad para la reforma de costumbres. Las terribles experiencias del siglo XIV -pestes y hambrunasseguían aún frescas en las memorias y a ello se sumaba el Gran Cisma (13781417). Estos elementos, considerados por muchos -incluyendo a San Vicentecomo signos del final, convirtieron a los auditorios de Ferrer en ávidos escuchas de las posibles explicaciones de su terrible realidad.

El sermón onceno de la campaña castellana tiene como objetivo la reforma de costumbres y la conversión de los judíos. Aunque estos objetivos parezcan disímiles, la estrategia discursiva de Ferrer es una sola, al mismo tiempo compleja y dinámica.

El judío emerge, a primera vista, como un destinatario unívoco. Sin embargo, encontramos que es en realidad un destinatario dinámico, cuyo lugar en el discurso es móvil y no-homogéneo. Al mismo tiempo hemos visto cómo la multiplicidad de formas de destinación a un sólo alocutario implica diversos sentidos. El rol del judío como adversario sirve de ejemplificación al colectivo de identificación y acaba por desnudar un verdadero contradestinatario: el infiel en el sentido amplio de la palabra. La definición de un adversario sindica a aquel que será excluido del colectivo de identificación que presenta el discurso. El locutor lo construye como una figura en la que se encarna la «inversión de la creencia», es decir de su propia creencia encarnada en el discurso que está enunciando ${ }^{58}$. Aquí el judío aparece como un otro discursivo que se mueve en los límites entre la exclusión y la inclusión a lo largo del discurso. El lugar tradicional del judío como adversario unívoco en los discursos de Ferrer es reemplazado en mi lectura por un adversario cuya inversión respecto de la creencia del locutor es absoluta y permite la construcción simultánea de un adversario -el infiel como ideal abstracto pero con asidero en la realidad- y

57. Remítase a la nota nro. 3 del presente trabajo.

58. Elíseo Verón, op. cit., p. 17. 
un adherente potencial cuyas características son identificables con el aspecto programático del discurso.

Al mismo tiempo -más aún, en las mismas enunciaciones- en que busca la conversión de los judíos, Ferrer interpela a los cristianos para que se conviertan en verdaderos cristianos. Así, una lectura uniforme del rol de los judíos en el discurso del "Campeón de la conversión" ${ }^{59}$ acaba cediendo su lugar a una comprensión más profunda del uso del estereotipo del judío por parte de uno de los detentadores de la "palabra autorizada».

La definición de un único anti-garante que excede los límites de la identificación religiosa es evidencia de que el adversario en el "Sermón onceno» es, antes que el judío, el infiel. El ethos del profeta, también orientado a cumplir ese objetivo, tiene como propósito el ser reconocido como un ser al que la divinidad ha elegido para traer un mensaje a todos los alocutarios, no sólo a los cristianos. La sumatoria de legitimidades expresada por el predicador en pos de asegurarse el ser oído como un verdadero enviado de Dios queda ligada a la pretensión universalista de la Iglesia que viene avanzando desde el siglo $\mathrm{XI}^{60}$. Ferrer representa la voz de la salvación de los hombres, considerados a priori como malos cristianos o no-cristianos.

La estrategia de persuasión es global y de igual modo está estructurado este discurso. Todas sus partes funcionan orgánicamente en la transmisión de un mensaje con un único sentido para todos los grupos de posibles alocutarios presentes. Así pues, el significado del discurso es, en última instancia, el mismo para todas sus audiencias: conversión o castigo.

59. Ferrer era considerado por sus contemporáneos un campeón de la «conversión voluntaria». Dice Alvar García de Santa María, en Crónica de Juan II, al referirse a la visita de San Vicente a tierras castellanas: «(...) con sus santas predicaciones convirtió a nuestra Sancta Fe a muchos judíos y moros é hizo muy grandes bienes (...)».Crónicas de los Reyes de Castilla, ed. Cayetano Rosell, Volumen II, Madrid, Atlas, 1953, p. 340. La hagiografía de San Vicente escrita por Justiniano de Antist en 1575 se hace eco de un sugestivo evento ocurrido en Salamanca: aparentemente Ferrer había hecho amistad con un judío que le servía y gracias a él logró entrar, escondido, a la sinagoga salmantina durante una de sus fiestas. El predicador, ya dentro de la sinagoga, se hizo ver con una cruz en la mano. La reacción, inicialmente negativa, es dominada por el santo quien los convence de oír sus palabras. La frialdad de los judíos ante su prédica provoca la ayuda divina. A través de un milagro las ropas de los judíos se incendian en fuego sagrado apareciendo en ellas cruces blancas. Todos los judíos de la sinagoga se convierten inmediatamente al cristianismo, tomando el nombre de «judíos vicentinos». Vicente Justiniano Antist, Vida e historia del apostólico predicador Sant Vicente Ferrer, Valenciano, de la orden de Santo Domingo, (1775) 1956, p. 172.

60. Brett E. Whalen, op. cit., passim. 